\title{
Assessing sensitivity to assumptions in mixed effects analyses of stepped-wedge trials
}

\author{
Calum Davey ${ }^{1}$, Jennifer A Thompson ${ }^{2 *}$ \\ From 3rd International Clinical Trials Methodology Conference \\ Glasgow, UK. 16-17 November 2015
}

\section{Background}

Stepped-wedge trials are used to evaluate the impact of interventions. Researchers often use mixed effects regression to estimate effects. This method includes within-cluster - non-randomised - comparisons that requires assumptions about the secular trends.

\section{Methods}

We simulated data from stepped-wedge trials with different characteristics. We analysed these data using a within-step only approach and mixed effects regression, and evaluated their performance. The within-step only approach preserves randomisation by combining estimates of effect from within steps using a weighted average; we used non-parametric bootstrapping to generate inferential statistics. We introduced violations of the mixed effects model assumptions and investigated the effects on the two methods.

\section{Results}

When the assumptions were met, the mixed effects method was more sensitive and specific than the withinstep approach. Bias was introduced to the mixed effects results by interaction of the secular trend with the clusters, and with the intervention. The within-step approach remained unbiased even in extreme violations of these assumptions. Comparing the mixed effects estimate of effect with the within-step estimate helped identify violations of the assumptions.

\section{Discussion}

We confirmed that mixed effects methods are more powerful than a within-step method when assumptions are met. Moderate to severe violations of assumptions

${ }^{2}$ MRC London Hub for Trials Methodology Research, MRC Clinical Trials Unit, University College London, London, UK

Full list of author information is available at the end of the article led to bias, supporting the need for clear reporting standards and sensitivity analysis for stepped-wedge trials. Estimating the within-step effect can be useful for identifying bias.

\section{Conclusion}

Within-step analyses that preserve the randomisation should be used as a diagnostic to assess the validity of common mixed effects methods for analysing steppedwedge trials.

\section{Authors' details}

'Department of Infectious Disease Epidemiology, London School of Hygiene and Tropical Medicine, London, UK. ${ }^{2}$ MRC London Hub for Trials Methodology Research, MRC Clinical Trials Unit, University College London, London, UK.

Published: 16 November 2015

doi:10.1186/1745-6215-16-S2-046

Cite this article as: Davey and Thompson: Assessing sensitivity to assumptions in mixed effects analyses of stepped-wedge trials. Trials 2015 16(Suppl 2):O46.

Submit your next manuscript to BioMed Central and take full advantage of:

- Convenient online submission

- Thorough peer review

- No space constraints or color figure charges

- Immediate publication on acceptance

- Inclusion in PubMed, CAS, Scopus and Google Scholar

- Research which is freely available for redistribution

Submit your manuscript at www.biomedcentral.com/submit
() Biomed Central 